\title{
Towards operational predictions of the near-term climate
}

\author{
Yochanan Kushnir ${ }^{1,25 \star}$, Adam A. Scaife $\oplus^{2,3,25 \star}$, Raymond Arritt ${ }^{4,26}$, Gianpaolo Balsamo $\odot^{5}$, \\ George Boer ${ }^{6}$, Francisco Doblas-Reyes ${ }^{78}$, Ed Hawkins ${ }^{\circ}{ }^{9}$, Masahide Kimoto ${ }^{10}$, Rupa Kumar Kolli" ${ }^{11}$, \\ Arun Kumar ${ }^{12}$, Daniela Matei ${ }^{13}$, Katja Matthes ${ }^{14,15}$, Wolfgang A. Müller ${ }^{13,16}$, Terence O'Kane ${ }^{17}$, \\ Judith Perlwitz ${ }^{18,19}$, Scott Power ${ }^{20}$, Marilyn Raphael ${ }^{21}$, Akihiko Shimpo ${ }^{22}$, Doug Smith2 \\ Matthias Tuma ${ }^{23}$ and $\mathrm{BoWu}^{24}$
}

\begin{abstract}
Near-term climate predictions - which operate on annual to decadal timescales - offer benefits for climate adaptation and resilience, and are thus important for society. Although skilful near-term predictions are now possible, particularly when coupled models are initialized from the current climate state (most importantly from the ocean), several scientific challenges remain, including gaps in understanding and modelling the underlying physical mechanisms. This Perspective discusses how these challenges can be overcome, outlining concrete steps towards the provision of operational near-term climate predictions. Progress in this endeavour will bridge the gap between current seasonal forecasts and century-scale climate change projections, allowing a seamless climate service delivery chain to be established.
\end{abstract}

T he evolution of climate over years and decades, up to a century or so, arises from three interactions: the response of the climate system to external forcing from anthropogenic and natural influences; interactions within and between the atmosphere, oceans, land surface and cryosphere; and interaction between externally forced and internally generated variability, for example, during volcanic eruptions and variations of solar flux.

Over recent decades, climate science has provided multidecadal to century-scale projections of future climate change in response to a range of anthropogenic and natural forcing scenarios $^{1}$, many of which have been produced and analysed through the Coupled Model Intercomparison Projects (CMIPs) ${ }^{2-4}$. The projections, and the detailed information derived from them, have been used to gain better understanding of the processes associated with the climate system's response to changes in external forcing and to inform governments of the long-term risks due to climate change $e^{5}$.

Externally forced climate model projections, of the kind performed under the CMIPs, show systematic climate change along pathways that are subject to the details of the prescribed forcing scenarios and model sensitivity. Each projected path is entwined with model-generated internal climate variability ${ }^{6}$. Starting from arbitrary initial conditions and integrated for a century or longer, the model internal variability is not expected to synchronize with internal variability in the real world. Multiple model realizations instead delineate a range of possible pathways resulting from the combination of forced and internal climate-system variability. The spread of the different model runs can be used to define an envelope of uncertainty due to internal variability and the models' climate sensitivity and systematic errors ${ }^{7}$.

The primary goal of near-term climate prediction (NTCP), by contrast, is to produce a skilful and reliable forecast of the actual evolution of both externally forced and internally generated components of the climate system. Near-term prediction systems use the present and projected anthropogenic forcing in the same way as long-term climate change projections do, but start from the observed climate state at the beginning of the prediction. Such predictions have been shown to have skill over a period of several years ${ }^{8-11}$. Decision-makers in many sectors of the economy, including those concerned with adaptation and resilience to climate variability and change, could benefit greatly from authoritative, skilful and reliable predictions of near-term climate ${ }^{12-14}$ (see also Box 1). In addition, the research and data sets generated by initialized coupled model decadal predictions provide knowledge

'Lamont-Doherty Earth Observatory, Earth Institute, Columbia University, Palisades, NY, USA. ${ }^{2}$ Met Office Hadley Centre for Climate Prediction and Research, Exeter, UK. ${ }^{3}$ College of Engineering, Mathematics and Physical Sciences, University of Exeter, Exeter, UK. ${ }^{4}$ Department of Agronomy, lowa State University, Ames, IA, USA. ${ }^{5}$ European Centre for Medium-range Weather Forecasts, Reading, UK. ${ }^{6}$ Canadian Centre for Climate Modelling and Analysis, Environment Canada and Climate Change, Victoria, British Columbia, Canada. ${ }^{7}$ ICREA, Pg. Lluis Companys, Barcelona, Spain. ${ }^{8}$ Barcelona Supercomputing Center, Barcelona, Spain. ${ }^{9}$ National Centre for Atmospheric Science, Department of Meteorology, University of Reading, Reading, UK. ${ }^{10}$ Atmosphere and Ocean Research Institute, University of Tokyo, Kashiwa, Japan. "World Climate Applications and Services Division, Climate Prediction and Adaptation Branch, Climate and Water Department, World Meteorological Organization, Geneva, Switzerland. ${ }^{12}$ Climate Prediction Center, College Park, MD, USA. ${ }^{13}$ Max Planck Institute for Meteorology, Hamburg, Germany. ${ }^{14}$ GEOMAR Helmholtz Centre for Ocean Research Kiel, Kiel, Germany. ${ }^{15} \mathrm{Christian-Albrechts-}$ Universität zu Kiel, Kiel, Germany. ${ }^{16}$ Deutscher Wetterdienst, Hamburg, Germany. ${ }^{17} \mathrm{CSIRO}$ Oceans and Atmosphere, Hobart, Tasmania, Australia. ${ }^{18}$ Cooperative Institute for Research in Environmental Sciences, University of Colorado, Boulder, CO, USA. ${ }^{19}$ Physical Sciences Division, NOAA/Earth System Research Laboratory, Boulder, CO, USA. ${ }^{20}$ Bureau of Meteorology, Melbourne, Victoria, Australia. ${ }^{21}$ University of California, Los Angeles, Los Angeles, CA, USA. ${ }^{22}$ Japan Meteorological Agency, Tokyo, Japan. ${ }^{23}$ WCRP/WMO, Geneva, Switzerland. ${ }^{24}$ LASG, Institute of Atmospheric Physics, Chinese Academy of Sciences, Beijing, China. ${ }^{25}$ These authors jointly supervised this work: Yochanan Kushnir, Adam A. Scaife. ${ }^{26}$ Deceased: Raymond Arritt. *e-mail: kushnir@ldeo.columbia.edu; adam.scaife@metoffice.gov.uk 


\section{Box 1 | Benefits of NTCP for preparedness and adaptation}

As the skill levels of NTCP indicate, there is considerable potential for such predictions to be widely beneficial for improving the management of important, real-world issues in a variety of different sectors. Just as in the case of seasonal prediction, which is already profitably used in various sectors such as agriculture ${ }^{95}$, transport ${ }^{96}$, energy ${ }^{97}$ and water resources ${ }^{98}$, there is much promise in NTCP. Examples of success in capturing this benefit are currently limited, primarily due to low awareness in the user community. It is a primary goal of the World Climate Research Program (WCRP) to increase the awareness of national climate services to this new product at the same time as the science community strives to increase its reliability and accessibility through overcoming the challenges listed in this Perspective.

NTCP aims to bridge the gap between the existing range of initialized predictions that extend from weather prediction to subseasonal and seasonal prediction and century-scale, uninitialized climate change projections. As emphasized above, NTCP incorporates the impact of both natural and anthropogenic external forcing, as well as internal interactions, in determining the future evolution of the climate system. In addition to benefits for the various sectors mentioned above, NTCP holds further value in the following areas:

- NTCP has shown to be a valuable source of information on multiannual tropical cyclone frequency that is relevant to the re-insurance industry.

- The utilization of decadal predictions will provide opportunities to validate the climate models and infrastructure used for climate change projections. This is because decadal prediction uses the same or largely similar coupled models to those used in climate projections. A similar paradigm has already been discussed in the use of seasonal predictions to: (1) calibrate climate change projections, and (2) develop users' confidence in climate change projection information, particularly when considering regional spatial scales.

- As the climate changes, there is great need for updated information on the current risk of extreme and unprecedented events. As such events are rare, there is limited information on them from observations. Annual-decadal climate predictions can offer early warning of where the risk of extreme events, due to both climate change and natural variability, is higher. This is possible even in regions where there is little near-term prediction skill, where the risk of extremes can be better estimated using large ensembles of hindcasts, such as those typically employed in near-term prediction. This approach was, for example, used to inform the UK government of current flooding risk in their 2016 National Flooding Resilience Review ${ }^{99}$ and see also Thompson and colleagues $^{100}$.

on the fidelity of model simulations of internal climate interactions, the response to external forcing and the underlying mechanisms. Both of these objectives are equally important to NTCP.

In this Perspective, we lay out the case for the operational provision of NTCPs, describe the remaining challenges to reaching these objectives and propose ways to overcome them. We also describe how the provision of NTCPs could become fully integrated into a temporally seamless range of forecast products, integrated into a temporally seamless range of forecast products, from weather forecasts through to subseasonal, seasonal, interannual, decadal and multi-decadal forecasts, as well as into the overarching delivery chain of climate services and products ${ }^{15}$.

\section{The case for operational NTCP}

The premise of NTCP is that the coupled climate system - the atmosphere, ocean, land and cryosphere - contains elements, interactions and responses that are predictable on interannual to decadal timescales, as schematically illustrated in Fig. $1^{16}$. NTCP depends on the ability of our coupled climate models to capture the predictable evolution of those climate system components that are represented in the initial conditions and respond realistically to the prescribed external forcing. It is part of the challenge of NTCP to effectively integrate available observations of the atmosphere, ocean, sea-ice and land-surface cover with information on external forcing to correctly prescribe and simulate the interactions and responses, and thus predict the system's future state. As part of CMIP5, an internationally coordinated experiment of such initialized decadal predictions took place ${ }^{17}$. Real-time prediction experiments are also underway, and are being produced each year?.

Sources of decadal predictability. Important external sources of decadal predictability are the components of anthropogenic forcing that are also essential to century-timescale projections, traditionally assessed by the IPCC. These are the current and projected concentrations of GHGs and the spatial distribution of industrial and natural aerosols. Other potential sources of predictability include the natural forcing by variations in solar irradiance ${ }^{18,19}$ and volcanic eruptions ${ }^{20,21}$. The quasi-regular 11-year solar cycle is arguably an important source of near-term predictive skill for the winter North Atlantic Oscillation and its hemispheric impacts ${ }^{22,23}$. Volcanic eruptions can affect the global climate by interfering with solar radiation and therefore triggering global and regional surface temperature and precipitation anomalies, and influence the natural patterns of atmospheric and oceanic circulation variability ${ }^{21,24}$. These eruptions are thought to be episodic and unpredictable at the lead time considered in NTCPs and therefore require special treatment ${ }^{20}$.

Internal climate variability is associated primarily with atmospheric teleconnection patterns and anomalies in surface conditions related to the state of the ocean, land surface, and sea ice ${ }^{16,25}$. Although large parts of the oceans exhibit sea surface temperature (SST) and upper ocean heat content variability on decadal and longer timescales, the North Atlantic and tropical Pacific stand out due to their global influence ${ }^{26}$. On long timescales, the North Atlantic displays a distinct multiyear SST variation, a phenomenon termed the Atlantic Multidecadal Oscillation (AMO) ${ }^{27}$ or Atlantic Multidecadal Variability (AMV) ${ }^{28}$ to indicate that the phenomenon may not be truly oscillatory. Observations and model simulations show that the AMV is anchored in the subpolar North Atlantic, but its footprint spreads over most of the northern ocean basin, particularly the tropical North Atlantic ${ }^{26,27}$. The AMV is associated with wide-ranging changes in surface climate over the circum-Atlantic continents ${ }^{27-29}$ and marine ecosystems ${ }^{30,31}$. The AMV expression in the tropical North Atlantic is reproduced in a number of CMIP5 models, although with some discrepencies ${ }^{32}$. The tropical expression of the AMV is particularly important for simulating and predicting the broader global impact of this Atlantic phenomenon on Sahel and Indian monsoon rainfall ${ }^{33,34}$ but the link between the subpolar gyre and the tropics remains poorly understood ${ }^{35}$. Coupled climate models suggest that ocean dynamics plays a role in the AMV and its expression in the subpolar gyre has been linked to variations in the strength of the Atlantic Meridional Overturning Circulation ${ }^{32,36}$ that contribute to its predictability ${ }^{35}$.

In the Pacific, decadal variability is manifested in what is collectively referred to as the Pacific Decadal Oscillation (PDO, also known as Pacific Decadal Variability (PDV) $)^{37,38}$. The phenomenon includes tropical and extratropical components that, when diagnosed from observed, low-pass-filtered SST variability, seem to be coherently linked ${ }^{37}$. However, this may not reveal its dynamical origin, which could include a combination of mechanisms 


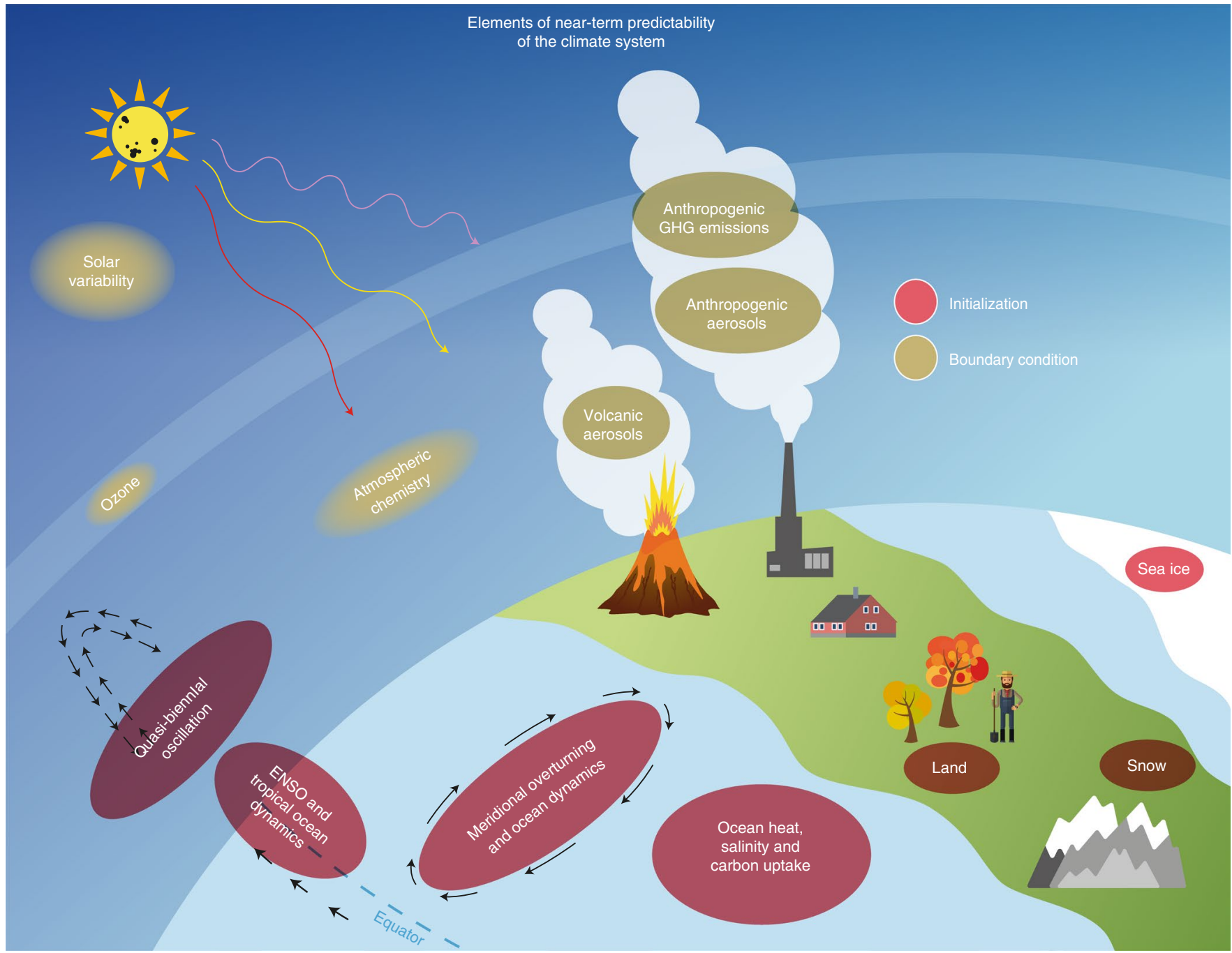

Fig. 1 | Internal and external elements of a near-term prediction system. The components of the climate system that affect near-term climate predictability (the atmosphere, ocean, land surface and cryosphere) are shown. Sources arising wholly or largely from initial conditions are shown in red, whereas sources wholly or largely arising from boundary conditions are in pale green. Black arrows indicate circulations in the atmosphere and ocean. Typical prediction systems do not yet include all of these sources of predictability. Figure (c) 2016, World Meteorological Organization.

such as coupled ocean-atmosphere interaction and local responses to remotely invoked atmospheric variability ${ }^{25,38}$. Of special interest is the primarily tropical, interbasin expression of PDV: the Interdecadal Pacific Oscillation (IPO). The IPO exerts a broad global influence that has been contrasted with that of the El Niño/ Southern Oscillation (ENSO) ${ }^{38,39}$. It has been implicated in global mean surface temperature change, in particular the recent slowdown in the rate of global surface warming that started around 1998 and ended recently ${ }^{40,41}$.

Other parts of the global ocean, the Indian, the Arctic and the Southern oceans, may also exhibit potentially predictable internal, long-term interactions ${ }^{16,26,42}$. These oceans play a significant role in determining the response of the climate system to external anthropogenic forcing. However, more research is necessary to resolve and elucidate the predictability of these interactions.

Forecast quality and adequacy for operational use. The skill of NTCP has been tested by performing retrospective predictions or 'hindcasts'. These are ensembles of initialized decadal predictions over select past time intervals that can be compared with observations ${ }^{43,44}$. This process is repeated enough times to produce an assessment of forecast quality during past decades. Such hindcastbased evaluation of NTCPs is essential if users are to develop confidence in the predictions, to highlight regions where forecasts have skill and to determine the associated uncertainties.

Recent studies of such hindcasts suggest that experimental near-term coupled model predictions are able to provide skilful information on the future evolution of various aspects of climate variability. This holds principally for surface air temperature and to some extent precipitation ${ }^{8-11,34,44-47}$ and also for the frequency of extreme events such as tropical storms or heatwaves ${ }^{48-50}$. From these and other studies we learn that predictions of temperature and precipitation typically show levels of skill that are comparable to predictions in operational seasonal forecasting (Fig. 2). The difference is in the temporal resolution of these predictions: for NTCP we are assessing the skill of multiyear averages, whereas the success of seasonal predictions is judged by evaluating at multimonth averages. The implication is that these two prediction systems may have a different level of forecast utility ${ }^{15}$. Empirically based predictions have also exhibited skill for surface air temperature and can provide a 'benchmark' for comparison with the global climate model-based forecasts ${ }^{51}$. 

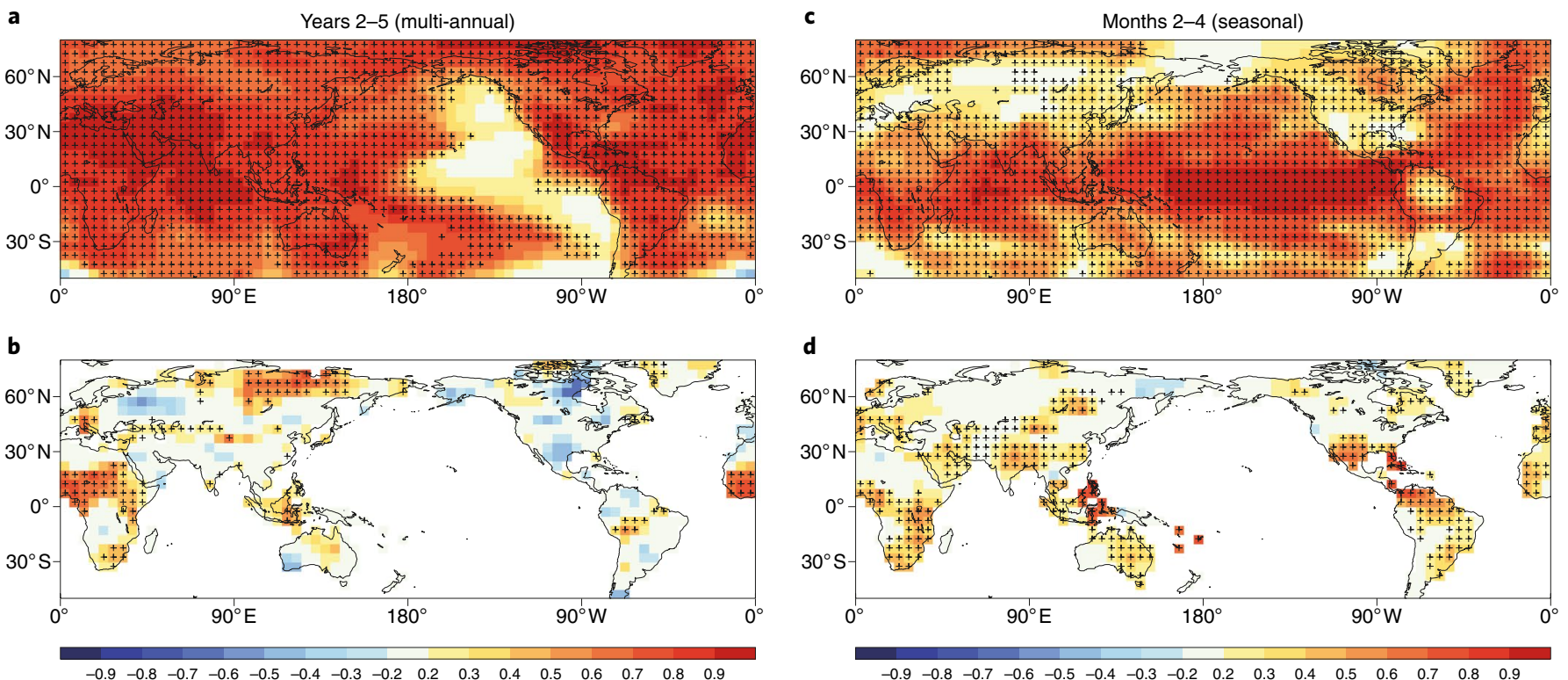

Correlation

Correlation

Fig. 2 | Near-term (decadal) forecast skill, compared with the skill of operational seasonal forecasts. a, The correlation between the years 2-5 average of predicted surface air temperature and observations. $\mathbf{b}$, The same as a but for precipitation. c, Correlation between the seasonal forecast for months $2-4$ of surface air temperature and observations. $\mathbf{d}$, The same as $\mathbf{c}$ but for precipitation. The near-term forecast skill in $\mathbf{a}$ and $\mathbf{b}$ was calculated from hindcasts performed by the UK Meteorological Office decadal prediction system DePreSys ${ }^{8}$, between 1960 and 2005 . The seasonal forecast skill in c and $\mathbf{d}$ was calculated from operational forecasts that were issued by one of the 12 Global Producing Centres of the $\mathrm{WMO}^{14}$.

While NTCP skill is mostly derived from the predictability associated with the prescribed external anthropogenic forcing, studies show that when the effect of GHG forcing on the prediction is removed, the skill levels remain comparable to those found in seasonal predictions ${ }^{17}$. In summary, just as for seasonal predictions, there is a clear case for developing the operational infrastructure needed for routine production of NTCPs to serve users who stand to benefit from this information (Fig. 2).

\section{Challenges to operational NTCP}

The CMIP5-initialized decadal climate prediction experiments and current ongoing decadal prediction activities reveal several impediments to progress towards providing effective NTCP information to society. These broadly fall in the following categories: understanding fundamental climate mechanisms, in particular those related to climate variability and predictability; addressing impeding aspects of climate modelling, especially reducing model systematic error and handling model shock, drift and bias; preparing initial conditions on the basis of suitable observations and developing new methods of forecast initialization and ensemble generation; co-development of prediction information formats with users, together with prediction uncertainty. Each of these points is discussed below.

Mechanisms of decadal variability and predictability. The two leading decadal phenomena, AMV and PDV, have been thought to arise primarily from interactions internal to the climate system. Yet understanding of the physical processes giving rise to these and other decadal climate variations, as well as their predictability, remains incomplete ${ }^{25,26}$. Such understanding is necessary to improve the models and gain confidence in their simulations and predictions.

Although transitions in the phase of the AMV seem to be predictable from initial conditions ${ }^{52,53}$, the effect of external anthropogenic and natural forcing on this phenomenon has also been debated $^{54-57}$. Understanding the sources of decadal variability in the Pacific and its predictability remains a challenging research problem $^{58,59}$. Atmosphere-ocean interaction within the tropics and the role of the extratropics have both been suggested, and the link between this phenomenon and ENSO is yet to be fully understood $^{38,60,61}$. It has furthermore been recognized that introducing the effect of external radiative forcing in decadal hindcast experiments improves the overall prediction skill of the $\mathrm{PDV}^{62}$. Complicating the matter, model studies provide evidence for an interplay between the $\mathrm{AMV}$ and $\mathrm{PDV}^{63-66}$ and for the possibility of interbasin interactions that affect global climate variability ${ }^{67,68}$. Such interactions may be represented in models but require further study ${ }^{69}$.

The role of natural forcing in decadal variability and prediction continues to be debated and analysed. New spectrally resolved solar irradiance values, as well as data on related energetic particle fluxes, are now available and will be used in CMIP6, where they will be tested for their impact on long-term projections and decadal prediction $^{70,71}$. The impact of volcanic eruptions on decadal prediction and their influence on the patterns of decadal variability is also an active area of study ${ }^{20,21}$ and plans have been made to investigate this as part of CMIP6, under the Volcanic Forcing Model Intercomparison Study $^{21}$ and the Decadal Climate Prediction Project (DCPP) ${ }^{69}$.

Bias, shock, drift and forecast initialization. Systematic errors in coupled model simulations of the mean climate, and model biases in particular, have been a long-standing concern and the subject of extensive research. Similarly, the fidelity of the pattern and amplitude of observed climate variability and change produced by models has been questioned, as this is crucial for gaining confidence in near-term prediction and for constraining forecast uncertainty ${ }^{72-75}$.

Because of their prevalent mean biases, climatologies of all coupled models used in NTCP differ from the observed climate. Documenting and understanding the origin of these biases so that they can be reduced and possibly eliminated is an ongoing goal of model development ${ }^{76}$. Partly as a consequence of such biases, inconsistencies arise between the observed initial conditions and 
the models' preferred state. These can generate shock and subsequently drift during climate predictions $s^{45,77,78}$. Therefore, initialization approaches employing the same model for both the generation of the initial state estimate and the prediction have been recommended but require further study ${ }^{45,79}$. Model shock and drift are not only the result of model biases, but can also be produced by imbalanced ocean and ocean-atmosphere initial conditions $s^{77,79-81}$. Methods of drift correction exist ${ }^{82,83}$ but could be further improved.

Another aspect of initialization is the choice between full-field and anomaly initialization ${ }^{81,84}$. In the first approach, the models' initial state is constrained to the full observed field. However, the models' state subsequently drifts during the prediction to their own climatology. In the second approach, deviations from climatology in observations are added to the model climatology, the model biases are not corrected and the predictions follow the deviations rather than the full field. Although they might ultimately converge as models are improved, each method has its advantages and drawbacks, and results depend on the predicted phenomena as well as on the prediction time and target region. However, in both cases predictions need to be bias-adjusted to be used in applications.

Using observations to prepare the initial conditions. The success of NTCP depends on the accurate specification of both initial and boundary conditions. The timescales involved in NTCP imply that the full ocean, as well as the land surface conditions (vegetation, snow and soil moisture) and cryosphere, are initialized as realistically as possible ${ }^{10,17}$. The present-day availability of in situ, surface and subsurface ocean observations and remote sensing from space, combined with the dynamical constraints imposed by numerical models, have made it possible to produce observationally consistent representations of the climatological ocean state ${ }^{85,86}$. The challenge is to develop methods to constrain the representation of the variability in the ocean state needed for a proper initialization of NTCP.

While methods to assimilate observational data for independent estimation of the ocean and/or atmosphere are improving, methods for the joint assimilation of observations in coupled climate systems are an emerging area of research ${ }^{87,88}$. In particular, an open research question concerns the treatment of related ocean and atmosphere data covariances, as well as the weighting of different observed variables in the various components of the climate system. Opportunities for rapid progress in NTCP initialization are provided by reanalysis comparisons and development activities of international efforts for example, the Ocean Reanalyses Intercomparison Project ${ }^{86}$.

Finally, in NTCP there is a need to generate an ensemble of predictions that best spans the probable future states of the climate system that are consistent with the initial condition. This requires adopting appropriate ways of perturbing the initial conditions when creating the ensemble. This process of ensemble generation requires further research. Research on post-processing of the ensembles and calibration of multi-model predictions is also required to enhance prediction skill and reliability, where the quality and precision of the observational datasets play a key role.

Co-development and communication of prediction information. The success of NTCP requires effective and reliable communication of the resulting information. Experience gained in communicating uncertainties in IPCC reports ${ }^{89}$ and in conveying risk prediction $^{90,91}$ can provide a useful start for corresponding endeavours in NTCP. To achieve that, there is a need to establish efficient exchange and NTCP information uptake among the prediction providers and between prediction providers and users. There is also a need to effectively build on experience from a longer history of operational seasonal predictions, which indicates that communicating probabilistic information, together with an increase in the uptake of information, requires a co-development process and the joint formulation of communication strategies ${ }^{92}$. Different users, depending on their experience with the use of prediction information, require information in various formats and content in terms of temporal and/or spatial granularity of the prediction, for example. Identifying and grouping prediction users according to their needs and codevelopment of relevant information formats will be an important task for the future, operational NTCP enterprise. It will also be important to develop appropriate pathways to obtain user feedback on how to improve prediction communication and to create products that utilize NTCPs.

\section{Moving forwards}

The WCRP recently initiated the Grand Challenge on NTCP (GC-NTCP) to "support research and development to improve multi-year to decadal climate predictions and their utility to decision makers" (https://www.wcrp-climate.org/gc-near-termclimate-prediction). To that end, the GC-NTCP identified several key actions and initiatives:

Promote international collaboration and intercomparison studies. CMIP6 promises a wide range of investigations that will shed new light on the defining challenges discussed above ${ }^{4}$. These investigations represent an opportunity for the improvement of models, analyses and understanding of the climate system, as well as providing a reassessment of NTCP under the $\mathrm{DCPP}^{69}$. In the latter, retrospective decadal climate predictions (performed by a range of participating climate modelling centres) will be created and made available for analysis. The results of this effort are fundamental to the development of bias adjustment, skill assessment, calibration and application of NTCP. A second DCPP objective is the ongoing production of real-time decadal predictions that would ultimately be translated into real-time, operational forecasts. The DCPP will also comprise idealized model experiments to probe the mechanisms of the global and regional climate response to PDV and AMV, the prediction potential of these and other modes of climate variability, and the effects of volcanic eruptions on near-term predictions.

Establishment of internationally agreed mechanisms to provide operational decadal predictions. Accredited procedures and infrastructure are needed for the operational provision of credible NTCP information. Technical regulations from the World Meteorological Organization (WMO) have recently established the roles and designation criteria for Global Producing Centres of Annual to Decadal Predictions (GPCs-ADCP). The WMO also designated a Lead Center for Annual to Decadal Climate Prediction (LC-ADCP) that will participate in and be responsible for the collection, coordination and dissemination of NTCPs. This is analogous to the existing infrastructure for seasonal-scale prediction ${ }^{14}$, in which the WMO GPCs of Long Range Forecasts (GPCs-LRF) and the Lead Center for Long-Range Forecast Multi Model Ensemble provide, respectively, individual and multimodel ensemble seasonal predictions, with a view towards the enhanced use of next generation climate models. This infrastructure is also supporting the development of a Global Seasonal Climate Update ${ }^{14}$, which is now in its trial phase and is expected to soon be operational.

Initiation and issuance of a yearly, real-time Global Annual to Decadal Climate Update. The GC-NTCP stresses the assessment, post-processing, combination and calibration of prediction results, with the goal of producing and disseminating actual, usable global NTCPs. Engaging in such an endeavour will result in better understanding of the available skill of the models, as well as suggest where improved skill might be sought. It will encourage investigations into climate system mechanisms and model aspects that determine skill. The ability to predict particular kinds of variability will also contribute to a better understanding of the mechanisms involved. Two major, current initiatives that are producing regular decadal, 
international multimodel predictions are the UK Met Office with its multimodel decadal prediction exchange ${ }^{9}$ and the Max Planck Institute for Meteorology decadal prediction effort, MiKlip ${ }^{93}$. As a preparation for, and transition towards, multimodel NTCP under the WMO and within the framework of accredited Global Producing Centres, an annually issued Global Annual to Decadal Climate Update is envisioned. This product would synthesize the output from real-time predictions in a standard report that will include an overview of the current observed state of the climate system and the external forcing agents, as well as predicted time series of key indices and maps for selected climate variables. An assessment of the skill and verification of previous predictions will also be provided following established standards (see below).

Production of standards, verification methods and guidance for near-term predictions. As has been done for seasonal forecasts, standards and protocols regarding the provision of decadal prediction by GPCs-ADCP and LC-ADCP have been developed under the auspices of the WMO, as part of its 2017 Manual on the Global Data Processing and Forecasting System. These define a clear process for the contributing centres seeking WMO accreditation as GPCs$\mathrm{ADCP}$, requiring commitment to the $\mathrm{WMO}$-specified products and fixed production cycles, as well as to prediction verification. These formal mechanisms should be accompanied by guidelines for the production of predictions that include a minimum ensemble size, bias correction methods, core prediction products and delivery schedules. Development of, and adherence to, such commonly agreed-on standards, structures and guidelines is a prerequisite to the success of the international operational provision of real-time NTCPs.

Promote and provide the new NTCP information to society. NTCP provides a key building block to satisfy the existing need for a broad end-to-end prediction system - a science-based process that links observations, modelling and prediction to concrete services for end-users. The availability of multiple centres producing near-term predictions will help in the characterization of forecast uncertainty and the determination of areas of agreement across predictions. It will also aid in identifying prediction strengths and weaknesses and the appropriate degree of confidence in providing reliable guidance for prediction users. The GC-NTCP has also been coordinating with the Global Framework for Climate Services (GFCS $)^{94}$ to extend the services it promotes by adding NTCP to the seasonal-to-interannual predictions and century-long, anthropogenic climate change projections it currently uses to provides climate information. The GFCS Implementation Plan recognizes that research on developing decadal climate prediction models is a special need of a range of users, given that the NTCP time span reflects a key planning horizon in decision-making. It is important that the GFCS process also includes user feedback that will enable the NTCP products to fit the users' demand for information. An end-to-end NTCP prediction systems will consist of, inter alia: (1) coupled atmosphere-ocean models; (2) the data used to initialize the models; (3) the generation and production of ensembles of predictions and their formulation into probabilities; (4) bias adjustment, post processing and assessment, together with methods of combining information from a group of models; (5) communication of predictions and uncertainty information to the users; and (6) mechanisms for feedback from the users on various aspects of decadal predictions. We expect that various downstream activities, such as dedicated impact modelling, adaptation planning and other applications that are needed to serve specific users, will also be developed in the future. The discussion of such applications and their development is outside the scope of this Perspective. We note however, that these applications will lead to added uncertainty in the final products.

\section{Conclusion}

We presented the scientific background and motivation for pursuing the routine provision of NTCPs, as well as recommendations for establishing and disseminating the predictions through a Global Annual to Decadal Climate Update. Predictions on this timescale, in addition to guidelines on prediction quality estimates, the origin of predictable signals and communication of uncertainty, are of direct relevance to stakeholders and decision-makers. Concerted efforts by the NTCP community should address a pressing societal need for climate information on decision-relevant timescales and encourage scientific research - as well as the generation of new knowledge. Coordinated initiatives on NTCP will provide an essential contribution to the GFCS by bridging the gap between seasonal predictions and long-term climate projections. The formal establishment of GPC-ADCPs by the WMO is a welcome development to help consolidate and streamline the contributions of the NTCP community worldwide. Such coordinated efforts will broaden the benefits of NTCP. It will ensure well-informed delivery and increase availability of NTCPs to national meteorological and hydrological services, and will provide regional climate centres with important information for accelerating the development of comprehensive climate services.

Received: 14 April 2018; Accepted: 13 November 2018; Published online: 21 January 2019

\section{References}

1. Collins, M. et al. in Climate Change 2013: The Physical Science Basis (eds Stocker, T. F. et al.) 1029-1136 (IPCC, Cambridge Univ. Press, 2013).

2. Meehl, G. A., Boer, G. J., Covey, C., Latif, M. \& Stouffer, R. J. The Coupled Model Intercomparison Project (CMIP). Bull. Am. Meteorol. Soc. 81, 313-318 (2000).

3. Taylor, K. E., Stouffer, R. J. \& Meehl, G. A. An overview of CMIP5 and the experiment design. Bull. Am. Meteorol. Soc. 93, 485-498 (2012).

4. Eyring, V. et al. Overview of the Coupled Model Intercomparison Project Phase 6 (CMIP6) experimental design and organization. Geosci. Model Dev. 9, 1937-1958 (2016)

5. IPCC Climate Change 2013: The Physical Science Basis (eds Stocker, T. F. et al.) (Cambridge Univ. Press, 2013).

6. Hawkins, E. \& Sutton, R. The potential to narrow uncertainty in projections of regional precipitation change. Clim. Dynam. 37, 407-418 (2011).

7. Murphy, J. M. et al. Quantification of modelling uncertainties in a large ensemble of climate change simulations. Nature 430, 768-772 (2004).

8. Smith, D. M. et al. Improved surface temperature prediction for the coming decade from a global climate model. Science 317, 796-799 (2007).

9. Smith, D. M. et al. Real-time multi-model decadal climate predictions. Clim. Dynam. 41, 2875-2888 (2013).

This paper provides an experimental prediction of the upcoming decade. Detailed global maps of predicted temperature change are shown, as well as time series of global mean temperature and other climate indices. It also demonstrates the impact of forecast initialization with correct concurrent information.

10. Meehl, G. A. et al. Decadal prediction: can it be skillful? Bull. Am. Meteorol. Soc. 90, 1467-1485 (2009).

This paper articulates the need for decadal predictions as a bridge between seasonal prediction and long-term climate change projections. It discusses which phenomena contribute to forecast skill, what the remaining scientific issues (at the time of writing) are and how forecasts should be evaluated.

11. Meehl, G. A. et al. Decadal climate prediction: an update from the trenches. Bull. Am. Meteorol. Soc. 95, 243-267 (2014).

12. Goddard, L. From science to service. Science 353, 1366-1367 (2016).

13. Hewitt, C. et al. Climate observations, climate modelling and climate services. Bull. Am. Meteorol. Soc. https://doi.org/10.1175/ BAMS-D-17-0012.1 (2017).

14. Graham, R. J. et al. Long-range forecasting and the Global Framework for Climate Services. Clim. Res. 47, 47-55 (2011).

This paper describes the infrastructure established by the World Meteorological Organization and the definition of operational standards to promote and support distribution of seasonal-to-interannual climate predictions. The paper also urges the development of decadal prediction capacity.

15. A European Research and Innovation Roadmap for Climate Services (European Commission, Directorate-General for Research and Innovation, 2015). 
16. Bellucci, A. et al. Advancements in decadal climate predictability: the role of nonoceanic drivers. Rev. Geophys. 53, 165-202 (2015).

17. Kirtman, B. et al. in Climate Change 2013: The Physical Science Basis (eds Stocker, T. F. et al.) 953-1028 (IPCC, Cambridge Univ. Press, 2013). This chapter of IPCC AR4 describes in detail the process of decadal prediction and presents the results of testing the concept within the framework of CMIP5.

18. Gray, L. J. et al. Solar influences on climate. Rev. Geophys. https://doi, org/10.1029/2009RG000282 (2010).

19. Thiéblemont, R., Matthes, K., Omrani, N.-E., Kodera, K. \& Hansen, F. Solar forcing synchronizes decadal North Atlantic climate variability. Nat. Commun. 6, 8268 (2015).

20. Timmreck, C., Pohlmann, H., Illing, S. \& Kadow, C. The impact of stratospheric volcanic aerosol on decadal-scale climate predictions. Geophys. Res. Lett. 43, 834-842 (2016).

21. Zanchettin, D. et al. The Model Intercomparison Project on the climatic response to Volcanic forcing (VolMIP): experimental design and forcing input data for CMIP6. Geosci. Model Dev. 9, 2701-2719 (2016).

22. Scaife, A. A. et al. A mechanism for lagged North Atlantic climate response to solar variability. Geophys. Res. Lett. 40, 434-439 (2013).

23. Dunstone, N. et al. Skilful predictions of the winter North Atlantic Oscillation one year ahead. Nat. Geosci. 9, 809-814 (2016).

24. Zanchettin, D. Aerosol and Solar Irradiance Effects on Decadal Climate Variability and Predictability. Current Clim. Change Rep. 3, 150-162 (2017).

25. Cassou, C. et al. Decadal climate variability and predictability: challenges and opportunities. Bull. Am. Meteorol. Soc. 99, 479-490 (2018).

26. Latif, M. \& Keenlyside, N. S. A perspective on decadal climate variability and predictability. Deep Sea Res. Pt II 58, 1880-1894 (2011). This review paper describes the key phenomena associated with decadal and multidecadal variability that is internal to the climate system and their underlying mechanisms and predictability. It pays special attention to the climate variability associated with the Atlantic Meridional Overturning Circulation.

27. Knight, J. R., Folland, C. K. \& Scaife, A. A. Climate impacts of the Atlantic Multidecadal Oscillation. Geophys. Res. Lett. 33, L17706 (2006).

28. Ting, M., Kushnir, Y., Seager, R. \& Li, C. Forced and internal twentiethcentury SST trends in the North Atlantic. J. Clim. 22, 1469-1481 (2009).

29. Zhang, R. \& Delworth, T. L. Impact of Atlantic multidecadal oscillations on India/Sahel rainfall and Atlantic hurricanes. Geophys. Res. Lett. 33, L17712 (2006)

30. Hátún, H. et al. Large bio-geographical shifts in the north-eastern Atlantic Ocean: from the subpolar gyre, via plankton, to blue whiting and pilot whales. Prog. Oceanogr. 80, 149-162 (2009).

31. Hátún, H. et al. An inflated subpolar gyre blows life toward the northeastern Atlantic. Prog. Oceanogr. 147, 49-66 (2016).

32. Zhang, L. \& Wang, C. Multidecadal North Atlantic sea surface temperature and Atlantic meridional overturning circulation variability in CMIP5 historical simulations. J. Geophys. Res. Oceans 118, 5772-5791 (2013).

33. Ruprich-Robert, Y. et al. Assessing the climate impacts of the observed Atlantic multidecadal variability using the GFDL CM2.1 and NCAR CESM1 Global Coupled Models. J. Clim. 30, 2785-2810 (2017)

34. Sheen, K. et al. Skilful prediction of Sahel summer rainfall on inter-annual and multi-year timescales. Nat. Commun. 8, 14966 (2017)

35. Yeager, S. \& Robson, J. Recent progress in understanding and predicting Atlantic decadal climate variability. Curr. Clim. Change Rep. 3, 112-127 (2017) This is a recent evaluation of the feasibility of coupled model-based predictions of the decadal variability of North Atlantic SSTs. A discussion of the link between the surface phenomenon and variation in the Atlantic Meridional Overturning Circulation is included.

36. Knight, J. R., Allan, R. J., Folland, C. K., Vellinga, M. \& Mann, M. E. A signature of persistent natural thermohaline circulation cycles in observed climate. Geophys. Res. Lett. 32, L20708 (2005)

37. Mantua, N. J., Hare, S. R., Zhang, Y., Wallace, J. M. \& Francis, R. C. A Pacific interdecadal climate oscillation with impacts on salmon production. Bull. Am. Meteorol. Soc. 78, 1069-1079 (1997).

38. Newman, M. et al. The Pacific Decadal Oscillation, revisited. J. Clim. 29, 4399-4427 (2016).

39. Dong, B. \& Dai, A. The influence of the Interdecadal Pacific Oscillation on temperature and precipitation over the globe. Clim. Dynam. 45, 2667-2681 (2015).

40. Kosaka, Y. \& Xie, S.-P. Recent global-warming hiatus tied to equatorial Pacific surface cooling. Nature 501, 403-407 (2013)

This is a pioneering paper that demonstrates that the long-term cooling of the eastern equatorial Pacific that began at the end of the twentieth century explains the slowdown in the rate of planetary warming that occurred in the following decade and a half

41. Meehl, G. A., Hu, A., Santer, B. D. \& Xie, S.-P. Contribution of the Interdecadal Pacific Oscillation to twentieth-century global surface temperature trends. Nat. Clim. Change 6, 1005-1008 (2016).
42. Han, W. et al. Indian Ocean decadal variability: a review. Bull. Am. Meteorol. Soc. 95, 1679-1703 (2014)

43. Boer, G., Kharin, V. \& Merryfield, W. Decadal predictability and forecast skill. Clim. Dynam. 41, 1817-1833 (2013).

44. Doblas-Reyes, F. et al. Initialized near-term regional climate change prediction. Nat. Commun. 4, 1715 (2013).

This paper provides a thorough evaluation of initialized decadal predictions skill, based on multi-model hindcasts, performed every five years between 1960 and 2005. It finds that globally, most of the forecast skill is attributable to the known external forcing in the past. Initial conditions can also provide skill in some parts of the world ocean.

45. Matei, D. et al. Two tales of initializing decadal climate prediction experiments with the ECHAM5/MPI-OM model. J. Clim. 25, 8502-8523 (2012).

46. Müller, W. A. et al. Forecast skill of multi-year seasonal means in the decadal prediction system of the Max Planck Institute for Meteorology. Geophys. Res. Lett. 39, L22707 (2012).

47. Bellucci, A. et al. An assessment of a multi-model ensemble of decadal climate predictions. Clim. Dynam. 44, 2787-2806 (2015).

48. Smith, D. M. et al. Skilful multi-year predictions of Atlantic hurricane frequency. Nat. Geosci. 3, 846-849 (2010).

49. Eade, R., Hamilton, E., Smith, D. M., Graham, R. J. \& Scaife, A. A. Forecasting the number of extreme daily events out to a decade ahead. J. Geophys. Res. Atmos. 117, D21110 (2012).

This paper assesses the predictability of daily temperature and precipitation extremes over various timescales (up to a decade), using a state-of-the-art decadal prediction system. When assessing extreme temperature predictions for the season ahead, the study finds modest, but significant, skill over Europe and North America. However, when predictions of extremes over time intervals of 5 to 10 years are examined, the forecast skill is found to increase due to reduced noise associated with the use of longer data records.

50. Caron, L.-P. et al. How skilful are the multi-annual forecasts of Atlantic hurricane activity? Bull. Am. Meteorol. Soc. https://doi.org/10.1175/ bams-d-17-0025.1 (2017).

51. Suckling, E. B., van Oldenborgh, G. J., Eden, J. M. \& Hawkins, E. An empirical model for probabilistic decadal prediction: global attribution and regional hindcasts. Clim. Dynam. 48, 3115-3138 (2017).

52. Robson, J., Sutton, R. \& Smith, D. Initialized decadal predictions of the rapid warming of the North Atlantic Ocean in the mid 1990s. Geophys. Res. Lett. 39, L19713 (2012).

53. Hermanson, L. et al. Forecast cooling of the Atlantic subpolar gyre and associated impacts. Geophys. Res. Lett. 41, 5167-5174 (2014).

54. Booth, B. B. B., Dunstone, N. J., Halloran, P. R., Andrews, T. \& Bellouin, N Aerosols implicated as a prime driver of twentieth-century North Atlantic climate variability. Nature 484, 228-232 (2012).

55. Murphy, L. N., Bellomo, K., Cane, M. \& Clement, A. The role of historical forcings in simulating the observed Atlantic multidecadal oscillation. Geophys. Res. Lett. 44, 2472-2480 (2017).

56. Zhang, R. et al. Have aerosols caused the observed Atlantic Multidecadal Variability? J. Atmos. Sci. 70, 1135-1144 (2013).

57. Otterå, O. H., Bentsen, M., Drange, H. \& Suo, L. External forcing as a metronome for Atlantic multidecadal variability. Nat. Geosci. 3, 688-694 (2010).

58. Ding, H., Greatbatch, R. J., Latif, M., Park, W. \& Gerdes, R. Hindcast of the 1976/77 and 1998/99 climate shifts in the Pacific. J. Clim. 26, 7650-7661 (2013).

59. Meehl, G. A., Hu, A. \& Teng, H. Initialized decadal prediction for transition to positive phase of the Interdecadal Pacific Oscillation. Nat. Commun. 7, 11718 (2016).

60. Power, S., Haylock, M., Colman, R. \& Wang, X. The predictability of interdecadal changes in ENSO activity and ENSO teleconnections. J. Clim. 19, 4755-4771 (2006)

61. Power, S. \& Colman, R. Multi-year predictability in a coupled general circulation model. Clim. Dynam. 26, 247-272 (2006).

62. Smith, D. M. et al. Role of volcanic and anthropogenic aerosols in the recent global surface warming slowdown. Nat. Clim. Change 6 , 936-940 (2016).

63. Xie, S. P., Okumura, Y., Miyama, T. \& Timmermann, A. Influences of Atlantic climate change on the tropical Pacific via the Central American Isthmus. J. Clim. 21, 3914-3928 (2008).

64. Kucharski, F. et al. Atlantic forcing of Pacific decadal variability. Clim. Dynam. 46, 2337-2351 (2016)

65. Chikamoto, Y., Mochizuki, T., Timmermann, A., Kimoto, M. \& Watanabe, M. Potential tropical Atlantic impacts on Pacific decadal climate trends. Geophys. Res. Lett. 43, 7143-7151 (2016).

66. Li, X., Xie, S.-P., Gille, S. T. \& Yoo, C. Atlantic-induced pan-tropical climate change over the past three decades. Nat. Clim. Change 43, 7143-7151 (2016) 
67. Chikamoto, Y. et al. Skilful multi-year predictions of tropical trans-basin climate variability. Nat. Commun. 6, 6869 (2015).

68. Tokinaga, H., Xie, S.-P. \& Mukougawa, H. Early 20th-century Arctic warming intensified by Pacific and Atlantic multidecadal variability. Proc. Natl Acad. Sci. USA 114, 6227-6232 (2017).

69. Boer, G. J. et al. The Decadal Climate Prediction Project (DCPP) contribution to CMIP6. Geosci. Model Dev. 9, 3751-3777 (2016). This paper describes the upcoming study of decadal prediction under CMIP6. This study will contribute to the issuance of the upcoming Global Annual to Decadal Climate Update by the WCRP GC-NTCP.

70. Gillett, N. P. et al. The Detection and Attribution Model Intercomparison Project (DAMIP v1. 0) contribution to CMIP6. Geosci. Model Dev. 9, 3685-3697 (2016).

71. Matthes, K. et al. Solar forcing for CMIP6 (v3. 2). Geosci. Model Dev. 10, 2247-2302 (2017).

72. Collins, M. et al. Challenges and opportunities for improved understanding of regional climate dynamics. Nat. Clim. Change 8, 101-108 (2018).

73. Eade, R. et al. Do seasonal-to-decadal climate predictions underestimate the predictability of the real world? Geophys. Res. Lett. 41, 5620-5628 (2014).

74. Power, S., Delage, F., Wang, G., Smith, I. \& Kociuba, G. Apparent limitations in the ability of CMIP5 climate models to simulate recent multi-decadal change in surface temperature: implications for global temperature projections. Clim. Dynam. 49, 53-69 (2017).

75. Cheung, A. H. et al. Comparison of low-frequency internal climate variability in CMIP5 models and observations. J. Clim. 30, 4763-4776 (2017).

76. Wang, C., Zhang, L., Lee, S.-K., Wu, L. \& Mechoso, C. R. A global perspective on CMIP5 climate model biases. Nat. Clim. Change 4, 201-205 (2014).

77. Pohlmann, H., Kröger, J., Greatbatch, R. J. \& Müller, W. A. Initialization shock in decadal hindcasts due to errors in wind stress over the tropical Pacific. Clim. Dynam. 49, 2685-2693 (2017).

78. Sanchez-Gomez, E., Cassou, C., Ruprich-Robert, Y., Fernandez, E. \& Terray, L. Drift dynamics in a coupled model initialized for decadal forecasts. Clim. Dynam. 46, 1819-1840 (2016).

79. Brune, S., Düsterhus, A., Pohlmann, H., Müller, W. A. \& Baehr, J. Time dependency of the prediction skill for the North Atlantic subpolar gyre in initialized decadal hindcasts. Clim. Dynam. 51, 1947-1970 (2017).

80. Kröger, J., Müller, W. A. \& von Storch, J.-S. Impact of different ocean reanalyses on decadal climate prediction. Clim. Dynam. 39 , 795-810 (2012).

81. Kröger, J. et al. Full-field initialized decadal predictions with the MPI earth system model: an initial shock in the North Atlantic. Clim. Dynam. 51, 2593-2608 (2017).

82. Kharin, V. V., Boer, G. J., Merryfield, W. J., Scinocca, J. F. \& Lee, W. S. Statistical adjustment of decadal predictions in a changing climate. Geophys. Res. Lett. 39, L19705 (2012).

83. Fučkar, N. S., Volpi, D., Guemas, V. \& Doblas-Reyes, F. J. A posteriori adjustment of near-term climate predictions: accounting for the drift dependence on the initial conditions. Geophys. Res. Lett. 41, 5200-5207 (2014).

84. Smith, D. M., Eade, R. \& Pohlmann, H. A comparison of full-field and anomaly initialization for seasonal to decadal climate prediction. Clim. Dynam. 41, 3325-3338 (2013).

85. Stammer, D. et al. In OceanObs 09: Sustained Ocean Observations and Information for Society (eds Hall, J. et al.) 979-989 (European Space Agency, 2010).

86. Balmaseda, M. et al. The ocean reanalyses intercomparison project (ORA-IP). J. Oper. Oceanogr. 8, s80-s97 (2015).

87. Laloyaux, P., Balmaseda, M., Dee, D., Mogensen, K. \& Janssen, P. A coupled data assimilation system for climate reanalysis. Q. J. R. Meteorol. Soc. 142, 65-78 (2016).
88. Penny, S. G. \& Hamill, T. M. Coupled data assimilation for integrated earth system analysis and prediction. Bull. Am. Meteorol. Soc. 98, ES169-ES172 (2017).

89. Budescu, D. V., Por, H.-H. \& Broomell, S. B. Effective communication of uncertainty in the IPCC reports. Climatic Change 113, 181-200 (2012).

90. Corner, A., Lewandowsky, S., Phillips, M. \& Roberts, O. The Uncertainty Handbook (University of Bristol, Bristol, 2015).

91. Spiegelhalter, D. Risk and uncertainty communication. Ann. Rev. Stat. Appl. 4, 31-60 (2017)

92. Buontempo, C. et al. What have we learnt from EUPORIAS climate service prototypes? Clim. Services 9, 21-32 (2018).

93. Marotzke, J. et al. MiKlip: a national research project on decadal climate prediction. Bull. Am. Meteorol. Soc. 97, 2379-2394 (2016).

94. Implementation Plan of the Global Framework for Climate Services (GFCS, 2014).

95. Hansen, J. W. Realizing the potential benefits of climate prediction to agriculture: issues, approaches, challenges. Agric. Syst. 74, 309-330 (2002).

96. Palin, E. J. et al. Skillful seasonal forecasts of winter disruption to the UK transport system. J. Appl. Meteorol. Climatol. 55, 325-344 (2016).

97. Clark, R. T., Bett, P. E., Thornton, H. E. \& Scaife, A. A. Skilful seasonal predictions for the European energy industry. Environ. Res. Lett. 12, ARTN 024002 (2017)

98. Wood, A. W. \& Lettenmaier, D. P. A test bed for new seasonal hydrologic forecasting approaches in the western United States. Bull. Am. Meteorol. Soc. 87, 1699-1712 (2006).

99. National Flood Resilience Review (DEFRA, 2016); https://go.nature. com/2BiyExQ

100. Thompson, V. et al. High risk of unprecedented UK rainfall in the current climate. Nat. Commun. 8, 107 (2017).

\section{Acknowledgements}

The authors form the scientific steering group of the WCRP GC-NTCP. The GC-NTCP is one of the international initiatives promoting and advancing science and standards for the coordinated provision of near-term climate predictions at global scale. T.O.K. was supported by the CSIRO Decadal Forecasting Project (https://research.csiro.au/dfp). S.P. is supported by the National Environmental Science Program's Earth Systems and Climate Change Hub. D.M. and W.A.M. were supported by the BMBF projects RACE II (D.M., grant no. FKZ:03F0729D) and MiKlip II (W.A.M., grant no. FKZ: 01LP1519A). The work of K.M. was partly supported by the BMBF within the nationally funded project ROMIC-SOLIC (grant no. 01LG1219) as well as within the frame of the WCRP/ SPARC SOLARIS-HEPPA activity. A.A.S. and D.S. were supported by the Joint DECC/ Defra Met Office Hadley Centre Climate under grant no. GA01101. E.H. was supported by the UK National Centre for Atmospheric Science and the SMURPHS project (grant no. NE/N006054/1). F.D.R. was supported by the H2020 EUCP (grant no. GA 776613) project.

\section{Author contributions}

Y.K. and A.A.S. wrote the paper with input from all other authors. M.T. provided editing, drafting and factual support.

\section{Competing interests}

The authors declare no competing interests.

\section{Additional information}

Reprints and permissions information is available at www.nature.com/reprints.

Correspondence should be addressed to Y.K. or A.A.S.

Publisher's note: Springer Nature remains neutral with regard to jurisdictional claims in published maps and institutional affiliations.

(c) Crown 2019 